\title{
Research Status of Element Distribution in Titanium Slag Smelting
}

\author{
Shihong Huang ${ }^{1, a}$, Xianhao Long ${ }^{2, *}$, Guangxian Luo ${ }^{3}$, Lei Wang ${ }^{4}$, Ting Lei ${ }^{5, *}$ \\ ${ }^{1}$ Office of Science and Technology, Kunming University, Kunming, China \\ ${ }^{2}$ Development Planning Office, Kunming University, Kunming, China \\ ${ }^{3}$ Chuxiong Quality of the Technical Supervision and Inspection Center, Chuxiong, China \\ ${ }^{4}$ Chuxiong Notary Office of Yunnan Province, Chuxiong, China \\ ${ }^{5}$ Kunming Metallurgy College, Kunming, China \\ a151688688@qq.com \\ *Corresponding author: longxh@kmu.edu.cn, Leiting@cymg.com
}

Keywords: titanium slag, element distribution.

\begin{abstract}
The distribution of titanium, calcium, magnesium, phosphorus, manganese and other elements in the high titanium slag smelting process has a great impact on the performance of the product. In this paper, the theoretical research and numerical simulation of element distribution in smelting process of high titanium slag in recent years are reviewed. Based on the mature theory of element distribution in the process of copper smelting, the basic law of element distribution in the process of titanium slag smelting in electric furnace was explored by combining experimental research with theoretical calculation.
\end{abstract}

\section{Introduction}

At present, the latest titanium slag smelting technology at home and abroad is smelting by direct current electric furnace ${ }^{[1]}$. The electric furnace smelting method uses anthracite or petroleum coke as a reducing agent. After batching and agglomerating with titanium concentrate, it is added to the electric arc furnace and smelted at a high temperature of $1600-1800{ }^{\circ} \mathrm{C}$. The products are metallic iron and titanium slag. According to the difference in specific gravity between pig iron and titanium slag, titanium oxide is separated from iron to obtain titanium slag containing $72 \sim 95 \% \mathrm{TiO}_{2}{ }^{[2]}$.

Compared with wet-process production of titanium-rich materials, DC electric arc furnace smelting high-titanium slag has lower requirements on the taste of concentrates, and does not produce some environmentally-polluting difficult-to-treat wastes such as $\mathrm{FeCl}_{3}, \mathrm{FeSO}_{4}$ and $\mathrm{Fe}_{2} \mathrm{O}_{3}$, and the process requirements are simple.

At present, in the titanium smelting process at home and abroad, the research focuses on the technological research of the titanium smelting process, mainly from the kinetics of the smelting process, and there are few research articles on the mechanism of metal titanium smelting, especially the trend of each element.

\section{Research overview of element distribution in the process of electric furnace smelting titanium slag}

Due to the importance of high-titanium slag products in the titanium industry, research on the production process of high-titanium slag has never stopped, and the experiment and research have been continuously carried out on the thermodynamics, kinetics, reaction mechanism and reaction process of the smelting process of high-titanium slag. The reduction thermodynamics of each component in ilmenite during the smelting process can be discussed using the Richardson-Gibbs diagram ( $\triangle \mathrm{G}$-T relationship diagram $)^{[3]}$, and the Gibbs free energy diagram can be used to intuitively 
give titanium The standard free energy of formation of various oxides in the iron ore composition varies with temperature, and the trend of selective reduction of each oxide is preliminarily determined. Figure 1 shows the Gibbs free energy diagram of each oxide in the composition.

In the process of ilmenite reduction, as the ratio of $\mathrm{TiO}_{3} / \mathrm{TiO}_{2}$ increases, the activity of $\mathrm{FeO}$ in the slag becomes smaller, and the reduction of $\mathrm{FeO}$ becomes more difficult. After the $\mathrm{FeO}$ in the slag is reduced to a certain extent, the FeO reduction is continued. The energy consumption will increase rapidly. The more fully FeO is reduced, the more low-priced titanium oxides, and the electric furnace smelting process becomes very difficult. The first is the increase of high melting point substances in the slag, which increases the melting point of the slag, increases its viscosity, deteriorates fluidity, and makes it difficult to slag. Secondly, the electrical conductivity of the slag increases significantly, and the electrical conductivity difference between the slag and the charge becomes larger, which makes the Electric furnace is difficult to receive electricity, uneven conduction, and difficult to operate power distribution. Because the low-valent oxide of titanium promotes the formation of $\mathrm{FeO} \cdot 2 \mathrm{TiO}_{2}-\mathrm{Ti}_{3} \mathrm{O}_{5}$ and $\mathrm{FeO} \cdot \mathrm{TiO}_{2}-\mathrm{Ti}_{2} \mathrm{O}_{3}$ solid solutions in the slag, the $\mathrm{FeO}$ activity is reduced, and the reduction continues, and high-grade high-grade For titanium slag, it is necessary to extend the reduction time and increase the reduction temperature, which in turn will cause a decrease in furnace energy and an increase in power consumption. It is not economical to reduce all $\mathrm{FeO}$ in the smelting process of high-titanium slag. Therefore, the $\mathrm{TiO}_{2}$ content of high-titanium slag produced by reduction smelting in large electric furnaces is generally not more than $90 \%$. CaO and $\mathrm{MgO}$ cannot be removed during the reduction process, but will be enriched, which increases the content of $\mathrm{CaO}$ and $\mathrm{MgO}$ in the slag. The high-titanium slag used as chlorination titanium dioxide requires $\mathrm{CaO}+\mathrm{MgO}<1 \%$ in the concentrate.

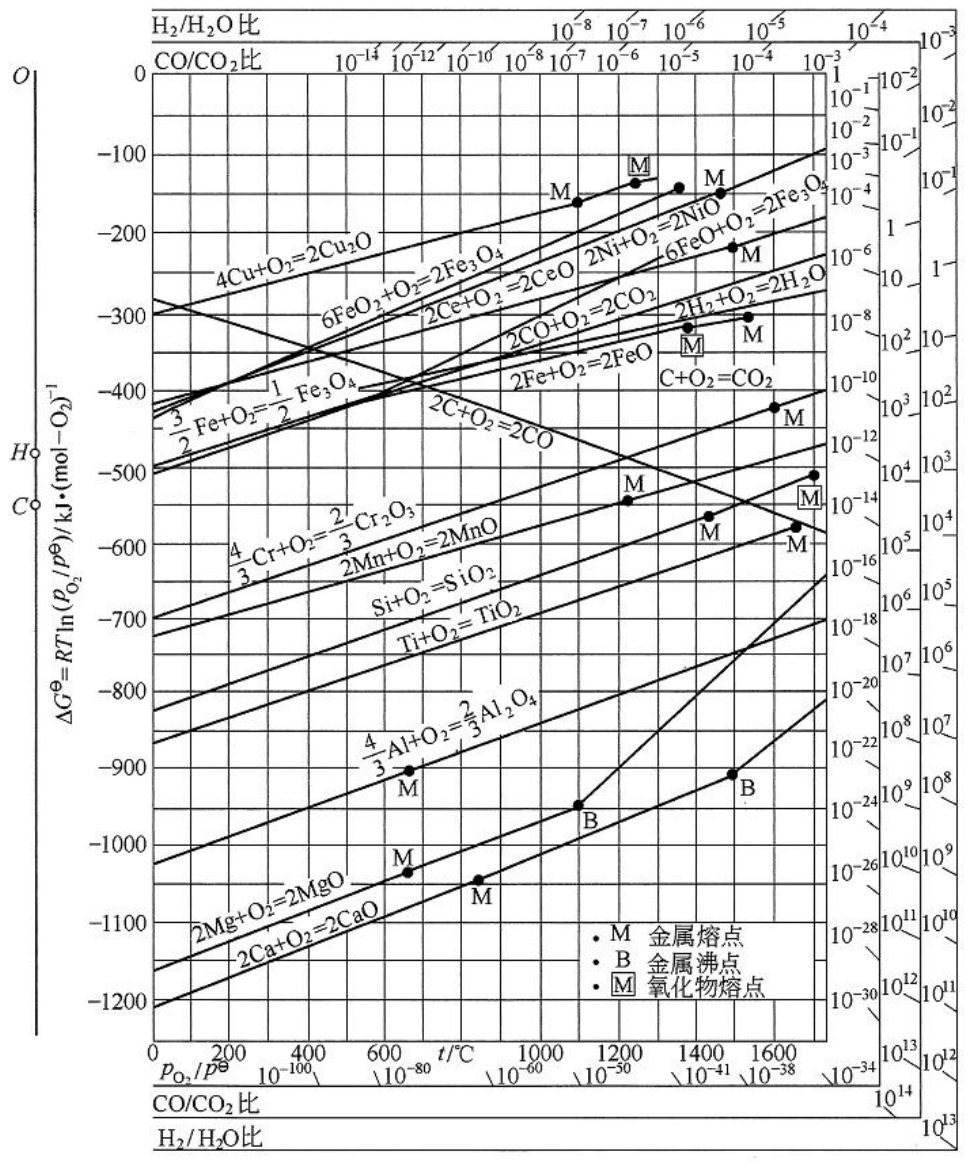

Fig. 1 Gibbs free energy diagram of oxide

It can be seen from Figure 1 that at a smelting temperature of about $2000 \mathrm{~K}$, the impurity elements $\mathrm{MgO}, \mathrm{Al}_{2} \mathrm{O}_{3}$ and $\mathrm{CaO}$ in ilmenite will not participate in the reduction reaction, and eventually these impurity elements will be enriched in the product high titanium slag; other impurity elements At this temperature, $\mathrm{MnO}, \mathrm{SiO}_{2}$ and $\mathrm{V} 2 \mathrm{O} 5$ will be partially reduced, and a small amount of $\mathrm{Mn}, \mathrm{Si}$ and $\mathrm{V}$ 
will be reduced and dissolved in the metallic iron phase. Since these impurities are far more difficult to be reduced than $\mathrm{FeO}$ and $\mathrm{TiO}_{2}$, most of the impurity elements in ilmenite will be enriched in high-titanium slag products.

Qu Yanping ${ }^{[4]}$ calculated the distribution coefficient of sulfur between slag and iron, and studied the desulfurization ability of high-titanium slag with $0-5 \% \mathrm{MnO}$ by using kinetic experiments. The results show that the partition coefficient increases with the increase of the initial content of $\mathrm{MnO}$ and the basicity of the slag, and decreases with the increase of the initial content of $\mathrm{TiO}_{2}$.

Sun Jian et al. $^{[5]}$ studied the electric furnace reduction smelting process of acidic vanadium-titanium slag, and studied the mass coefficient of vanadium distribution between molten iron and titanium slag to investigate the thermodynamics and reduction kinetics. The experiment investigated the influence of changes in these parameters on the reduction reaction of vanadium oxide during the smelting process by setting the mass ratio of titanium slag and molten iron, reaction temperature, initial $\mathrm{V}_{2} \mathrm{O}_{5}$ content, initial $\mathrm{TiO}_{2}$ content, initial FeO content, etc. The test results show that : The increase of the reaction temperature, the greater the amount of molten iron and the greater the initial content of $\mathrm{V}_{2} \mathrm{O}_{5}$ in the slag, are all beneficial to the reduction of $\mathrm{V}$. The higher the initial content of $\mathrm{FeO}$ and $\mathrm{TiO}_{2}$ in the slag, the more unfavorable the reduction of $\mathrm{V}$ and the lower the reaction rate. The phase composition of the slag includes magnesia garnet with a small amount of diopside, magnesia with a small amount of iron oxide, and a large amount of Ti present in the magnesia. At the initial stage of the reduction reaction, when the vanadium oxide reduction rate is $28 \%$ to $38 \%$, most of $\mathrm{Ti}$ is present in the elongated $\mathrm{Mg}_{3} \mathrm{Al}_{4} \mathrm{Ti}_{3} \mathrm{O}_{25}$ and $\mathrm{MgTi}_{2} \mathrm{O}_{5}$ solid solution phases, and a small part is dispersed in the silicate phase and small granular phases. As the reduction reaction progresses, Ti gradually precipitates out of the silicate phase, combines with small granular materials, aggregates and grows into a strip of $\mathrm{Mg}_{3} \mathrm{Al}_{4} \mathrm{Ti}_{3} \mathrm{O}_{25}$ and $\mathrm{MgTi}_{2} \mathrm{O}_{5}$ solid solution phases, and finally exists in this phase. At the initial stage of the reaction, when the vanadium oxide reduction rate is $28 \%$ to $38 \%, \mathrm{~V}$ is mainly present in the small granular and long Ti-containing phases, and closely coexists with $\mathrm{Ti}$. As the reduction reaction proceeds, $\mathrm{V}$ is gradually The reduction enters into the molten iron. At the later stage of the reaction, when the vanadium oxide reduction rate is $71 \%-77 \%$, the remaining unreduced $\mathrm{V}$ is present in the silicate phase.

Wang Yanzhong et al. ${ }^{[6]}$ conducted a thermodynamic analysis of the relevant reactions of electric furnace smelting ilmenite in the Panzhihua Iron and Steel Research Institute and believed that the free $\mathrm{FeO}$ and $\mathrm{Fe}_{2} \mathrm{O}_{3}$ in the ilmenite during the electric furnace smelting process were first reduced, and then the main component of the ilmenite $\mathrm{FeTiO}_{3}$ It is gradually reduced in the following order: $\mathrm{FeO} \cdot \mathrm{TiO}_{2} \mathrm{yFe} \rightarrow \mathrm{TiO}_{2} \mathrm{yFe} \rightarrow \mathrm{Ti}_{3} \mathrm{O}_{5} \mathrm{yFe} \rightarrow \mathrm{Ti}_{2} \mathrm{O}_{3} \mathrm{yFe} \rightarrow \mathrm{TiO}$. Impurities such as $\mathrm{MgO}, \mathrm{Al}_{2} \mathrm{O}_{3}$ and $\mathrm{CaO}$ are basically not reduced at the temperature of ilmenite smelting by electric furnace reduction and smelting at around $2000 \mathrm{~K}$, and are finally enriched in the product high titanium slag; the main phase of the high titanium slag obtained by electric furnace smelting is black titanium and vitreous silicon Salt phase.

Zhao Zhijun et al. ${ }^{[7]}$ studied how to increase the enrichment of $\mathrm{V}$ in metallic Fe, and studied the relationship between the reaction rate of iron oxides and temperature when ilmenite was reduced by anthracite. They produced iron oxides. The relationship between the logarithm of the standard reaction rate and the reciprocal temperature is shown in Figure $2^{[8]}$. It can be seen from Figure 2 that when the reaction temperature is between $1170 \mathrm{~K}$ and $1570 \mathrm{~K}$, increasing the temperature can significantly increase the reaction rate. Early research on the smelting process of high-titanium slag also found that the chemical composition of high-titanium slag has always maintained the composition of the theoretical compound M3O5, and its cations $\mathrm{M}$ are mainly $\mathrm{Fe}^{2+}$ and $\mathrm{Ti}^{3+}$, but the specific formation mechanism of this form is not clear. 


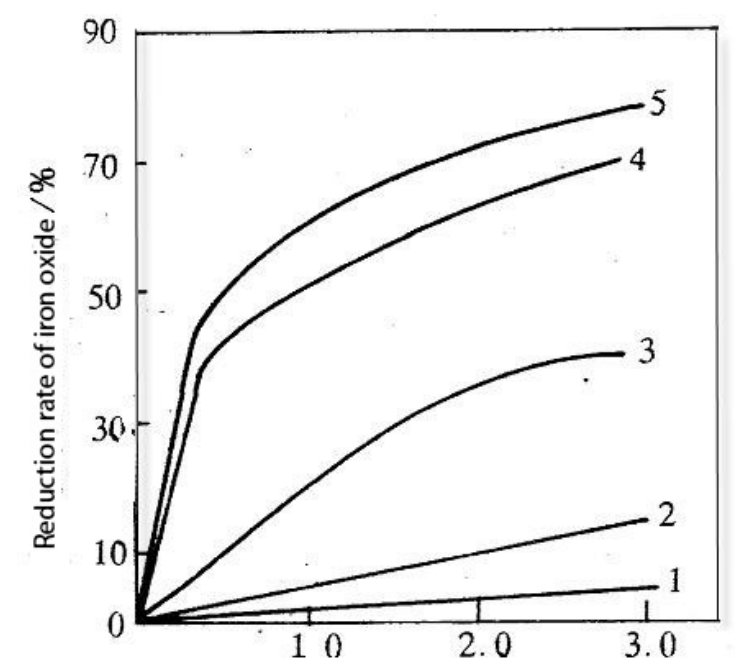

1-1173K; 2-1273K; 3-1373K; 4-1473K; 5-1573K

Fig. 2 Iron oxide reduction rate of reduction of titanium ore anthracite on different temperatures

Kucukkaragoz et al. ${ }^{[8]}$ found that the reduction process of ilmenite under anthracite conditions can be divided into two stages: the first stage is a solid-state reduction process, and high-valence Fe and $\mathrm{Ti}$ undergo $\mathrm{Fe}^{3+} \rightarrow \mathrm{Fe}^{2+} \rightarrow \mathrm{Fe}$ and $\mathrm{Ti}^{4+} \rightarrow$ In the $\mathrm{Ti}^{3+}$ reduction process, the reduction level can reach $50 \%$; the second stage is the remaining about $50 \%$ of the Ti compound participating in the reduction reaction, the process is $\mathrm{Ti}^{3+} \rightarrow \mathrm{Ti}^{2+}$, and finally $\mathrm{TiO}^{1-\mathrm{x}}$ is produced. This stage is the melting and slagging process.

Han Fengxia et al. ${ }^{[9]}$ studied the effect of the carbon ratio of high-titanium slag smelted with 30MVA DC electric arc furnace on the reduction reaction of $\mathrm{FeO}$ in ilmenite and other difficult-to-reducible oxides (such as $\mathrm{MgO}, \mathrm{CaO}, \mathrm{MnO}$, etc.). Adjusting the carbon ratio can improve the quality of $\mathrm{TiO}_{2}$ in the high titanium slag, and its content can be increased from $82 \%$ to over $89 \%$. However, the mass balance of the materials used does not include the dust carried away by flue gas, so there is a certain error in the calculation.

H.M.ЧуЙ $\mathrm{ko}^{[10]}$ demonstrated from the perspective of theory and practice based on the coexistence theory of slag structure, and made great contributions to the distribution of phosphorus, oxygen and manganese in the multi-element slag melt. However, there are also problems such as complicated calculations and the need to add a correction coefficient to the equilibrium constant. Secondly, the demonstration is not enough.

It can be seen that in the high-titanium slag smelting process at present, the research focuses on the technological research of the titanium smelting process, mainly from the kinetics of the smelting process, and there are few research articles on the smelting mechanism of high-titanium slag, especially the trend of each element. .

\section{Theoretical research and numerical simulation of element distribution in the process of titanium slag smelting in electric furnace}

Tan Pengfu et al. ${ }^{[1-13]}$ proposed a computer model of the distribution behavior of arsenic, antimony and secretion in the copper smelting process. The model simulates the operating conditions of the actual copper smelting production process, and its simulation results are in good agreement with the collected production data. The equations contained in the model are approximated by Newton-Raphson method and realized by computer programming. The error of the obtained results is small. In addition, it also proposed a computer model of the distribution behavior of associated elements during copper smelting.Studies have shown that: in the iron silicate slag system and the calcium ferrite slag system, the distribution rate of the associated elements tin, lead, zinc, potassium, antimony, and bismuth in the gas phase increases with the increase of the smelting temperature.

Zhang Chuanfu et al. ${ }^{[14]}$ studied the distribution of antimony, arsenic, antimony, and bismuth in slag, sulfur, gas phase and blister copper, and analyzed their molecular morphology in copper 
smelting and their distribution behavior in copper smelting.

Tan Pengfu et al. ${ }^{[15]}$ developed a computer model of the distribution behavior of trace elements and associated elements in copper smelting with the aid of multi-phase and multi-component system equilibrium calculation, trace elements which is arsenic, antimony, and bismuth. associated elements which is lead and zinc, The model was used to simulate the copper smelting process by computer, and the influence of matte grade on the partial pressure and activity coefficient of impurity elements such as arsenic, antimony, bismuth, lead and zinc and their distribution rate in the matte, slag and gas phase were analyzed. Influence, and discuss the guiding significance of its thermodynamic analysis results to production practice.

Dong Jinming et al. ${ }^{[16]}$ analyzed the distribution behavior of $\mathrm{V}$ between $\mathrm{FeO}-\mathrm{SiO}_{2}-\mathrm{MnO}\left(\mathrm{TiO}_{2}\right)$ slag phase and molten iron, and studied the influence of the temperature, slag-to-iron ratio, slag composition, and the initial Si and Ti content in molten iron on the distribution behavior of $\mathrm{V}$. The results show that in the $\mathrm{FeO}-\mathrm{SiO}_{2}-\mathrm{MnO}$ system, the distribution ratio of $\mathrm{V}$ in the slag- molten iron phases and the content of $\mathrm{V}$ in the slag decrease with the increase of temperature, while the oxidation loss of $\mathrm{C}$ in the molten iron will increase with the increase of temperature. Increase; the slag entering rate of $\mathrm{V}$ decreases with the decrease of slag iron. When the content of $\mathrm{MnO}$ is $13 \%-25 \%$ and the content of $\mathrm{SiO}_{2}$ is $12 \%-24 \%$, the slag entering rate of $\mathrm{V}$ is the largest. In the $\mathrm{FeO}-\mathrm{SiO}_{2}-\mathrm{MnO}-\mathrm{TiO}_{2}$ system, as the content of $\mathrm{TiO}_{2}$ in the slag increases, the slag entering rate of $\mathrm{V}$ in the molten iron, the distribution ratio of $\mathrm{V}$ in the slag- molten iron phase and the mass of vanadium in the slag continue to decrease. In addition, $\mathrm{V}_{2} \mathrm{O}_{3}$ The activity coefficient in the slag will increase with the increase of $\mathrm{TiO}_{2}$ content. Under the test conditions, the influence of various factors on the slag entering rate of $\mathrm{V}$ in the molten iron is arranged in the following order: composition of the slag>temperature $>$ initial $\mathrm{Si}$ and $\mathrm{Ti}$ content of the molten iron.

In summary, past researchers have conducted certain studies on the process and mechanism of the smelting process of high-titanium slag, but these studies focus on the description of the process, and there are insufficient thermodynamic studies on the smelting process. The mechanism expression of the smelting process of ore is relatively lacking for ferro-titanium in Yunnan Province. In addition, the research on the kinetic model and mechanism of the multi-element and multi-phase metallurgical separation process of the high-titanium slag smelting process is very imperfect.

\section{Conclusions}

There are many problems worth studying in the distribution of elements in the process of titanium slag smelting in electric furnace, mainly in the following aspects

(1) The relevant theoretical research on the distribution of elements in the process of titanium slag smelting in electric furnace, which can start from the following aspects: learn from the existing relatively mature theories of element distribution in the copper smelting process, and establish through the combination of experimental research and theoretical calculations, The mathematical model of the distribution behavior of $\mathrm{Ti}, \mathrm{Ca} \mathrm{Mg}, \mathrm{P}, \mathrm{Mn}$ and other elements in the titanium slag smelting process, and with the help of the chemical equilibrium calculation method in the multi-phase and multi-component system, the distribution behavior of titanium and associated elements in the smelting process is carried out. Mathematical description to reveal the law of element distribution of titanium slag smelting process in the electric furnace.

(2) Study the influence of process parameters on element distribution behavior of titanium slag smelting process in the electric furnace, control and adjust it, which can provide a theoretical basis for production.

(3) The key issue of element distribution in the process of titanium slag smelting by electric furnace is the collection of relevant thermodynamic data and the calculation of multi-component system and multi-phase equilibrium, determining the Gibbs free energy and activity coefficient of each component in the equilibrium state, and calculating the moles of each element in different phases, and finally get the distribution rate of the elements in each phase, and the verification of the model. 


\section{Acknowledgments}

This work was financially supported by Yunnan Local Colleges Applied Basic Research Projects (2017FH001-053) and The Scientific Research Fund Project of Education Department of Yunnan Province (No.2018JS394).

\section{References}

[1] J.F. Sheng. Re-analysis of the characteristics of direct current-hollow electrode smelting titanium slag [J]. Titanium Industry Progress, 2004, 21(1):128

[2] B. Wang, K.R. Liu, J.S. Chen, T.Y. Gao, J.L. He. Preparation of V-Ti-Fe master alloys by metallothermic reduction method. Trans. Nonferrous Met. Soc. China, 2012 (22) :1507-1512

[3] W. Mo, G.Z. Deng, F.C. Luo. Titanium Metallurgy (Second Edition)[M]. Beijing: Metallurgical Industry Press, 1998.

[4] Y.P. Qu, G.C. Shao. Study on Desulfurization Kinetics of MnO High Titanium Slag[J]. Journal of Shenyang University of Technology, 1998, 20(2): 24-28.

[5] J. Sun. Thermodynamics and Kinetics of the Reduction for Acid Vanadium-titanium Slags in Electric Furnace [D]. Kunming: Master's Thesis of Kunming University of Science and Technology, 2008.

[6] Y.Z. Wang, G.S. Zeng, Y. Zhu, J.S. Zhang, A thermodynamic analysis of the reduction smelting of ilmenite [J]. Southern Metal, 2004, 138: 10-13.

[7] Z.J. Zhao, M.A. Quan. Feasibility study on reducing vanadium content in high titanium slag by electric furnace smelting[J]. Titanium Industry Progress, 2002, 6: 41-43.

[8] Kucukkaragoz C S, Eric R H. Solid state reduction of a natural ilmenite [J]. Minerals Engineering, 2006, 19 (3): 334.

[9] F.X. Han, T. Lei, L. Zhou, S.H. Huang, G.G. Lv. Ratio of Anthracite to Ilmenite of Titanium Slag Smelted by 30 MVA DC Arc Furnace [J]. Rare Metals, 2012, 36(02): 297-303.

[10] N.M. Chuiko, H.M. ЧуЙko. Distribution of phosphorus between liquid iron and slag in consideration of ionic and covalent bonds in compouds of slag [J], Metall. And Fuels, 1960,

[11] P.F. Tan, C.F. Zhang, Z.G. Li, D.W. Zeng. A Computer Model of the Distribution Behavior of Group VA Elements in the Copper Smelting Process[J]. Journal of Central South University of Technology, 1995, 26 (4): 479-483.

[12] P.F. Tan, C.F. Zhang. Computer model of the distribution behavior of associated elements during copper smelting[J]. Acta Metallurgica Sinica, 1997, 33 (10): 1094-1100.

[13] P.F. Tan, C.F. Zhang. The effect of melting temperature on the distribution of associated elements in copper smelting[J]. Nonferrous Metals, 1998, 50 (12): 58-62.

[14] C.F. Zhang, P.F. Tan, D.W. Zeng, Z.G. Li, S.M. Xu. Molecular morphology of arsenic, antimony and bismuth in copper smelting[J].Journal of Central South University of Mining and Metallurgy.1994, 25 (6) 706-709.

[15] P.F. Tan, C.F. Zhang. The effect of matte grade on the distribution of impurity elements in copper smelting[J]. Nonferrous Metals. 1997, 49(3) 65-68.

[16] J.M. Dong, F. Zhao, Y.L. Zhang, S.T. Qiu, Y. Gan. Distribution Behaviors of Vanadium between Hot Metal and $\mathrm{FeO}-\mathrm{SiO}_{2}-\mathrm{MnO}\left(-\mathrm{TiO}_{2}\right)$ Slag System and Influential Factors[J]. The Chinese Journal of Process Engineering, 2010, 10(6)1076- 1083. 